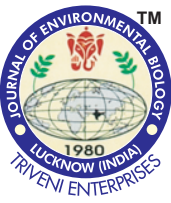

\title{
Developmental dynamics in chemical composition during fruit ripening of pomegranate
}

\section{Authors Info}

\section{A. Kumar* and P.S. Gill}

Department of Fruit Science, Punjab Agricultural University, Ludhiana-141 004, India

*Corresponding Author Email : alok-fs@pau.edu

Key words Arils juice, Fruit ripening, Major chemical composition, Pomegranate, Total phenolics

\section{Publication Info}

Paper received : 17.03 .2016

Revised received : 01.08 .2016

Re-revised received : 15.09 .2016

Accepted: 07.10 .2016

\section{Abstract}

Aim: The present study was undertaken to investigate the influence of pomegranate fruit developmental and maturity stages on the major chemical composition of pomegranate juice to identify the appropriate time of maturity of pomegranate cv. "Mridula".

Methodology: Fresh fruits of eight-year-old plants of pomegranate cv. 'Mridula' were picked manually in the morning at different developments stages, viz., 30 to 150 DAFB at ten day interval. Harvested fruits were analysed for physico-chemical analysis.

Results: Pomegranate arils juice showed a significant $(p<0.05)$ increase in sugars and soluble solids content during fruit development. However, titratable acidity and total phenolics of aril juice decreased with advancement of fruit maturity. There was 11.32 times increase in Vitamin $\mathrm{C}$ content of juice during fruit development, whereas about 2.38 fold decrease in juice acidity was recorded. The reducing sugars content in aril juice was about $76.35 \%-81.93 \%$ of total sugars. There was overall depletion of total phenolics content during course of fruit development. The results revealed that soluble solids content, SSC/TA ratio, juice $\mathrm{pH}$, reducing sugars, non-reducing sugars, total sugars and Vitamin $\mathrm{C}$ of juice was abundant between 140-150 days after full bloom (DAFB). Whereas, TA and TP declined and reached minimum between 140150 DAFB. SSC/TA ratio showed positive correlation with $\mathrm{pH}$, sugars and Vitamin C, but negatively correlated with TA and TP. The principal components analysis showed that full ripened fruit at 140-150 DAFB recorded higher positive score along component 1 and indicate optimum time of fruit harvest.

Interpretation: In recent years, the search for a easy, reliable and simple determination of maturation has employed the attention of countless pomegranate growers in different pomegranate production regions. The change in the chemical profile of pomegranate from 30 DAFB to 150 DAFB of arils juice clearly explained their growth, development and maturity stages. This information would help pomegranate growers to access the maturity of 'Mridula' cultivars of pomegranate.
Optimum time for fruit harvesting of pomegranate Cv. "Mridula"

\section{Good Agriculture Practices}

Pomegranate fruit harvested after 30 DAFB at 10 day interval till complete ripening stage reached.

Physico-chemical changes analyzed such as soluble solids contents, titratable acidity, soluble solids contents/titratable acidity ratio, $\mathrm{pH}$, total sugars, reducing sugars, non-reducing sugar, Vitamin $\mathrm{C}$ and total phenolics.

Soluble solids contents, soluble solids contents/ titratable acidity ratio, total sugar, reducing sugar, non-reducing sugar, $\mathrm{pH}$, Vitamin $\mathrm{C}$ increases with ripening of fruits but titratable acid and total phenolics decrease with ripening.

Maturity assessment

Optimum time for fruit harvesting fix around 150 DAFB 


\section{Introduction}

Pomegranate fruits are important for human health because of their high antioxidant capacity and high polyphenols and anthocyanins content (Gil et al., 2000). The quality of pomegranate fruits is strongly dependent on the cultivars. The acceptability of pomegranate to the consumer and processor depends on aggregate of certain quality attributes that are related to the physico-chemical properties inclusive of size, skin colour, sugar content, TA and flavour (Al-Said et al., 2009). The pomegranate fruit is non-climateric in nature and the timing of harvest is of at most importance if fruit, either for immediate fresh market or for storage, are to reach the customer in prime condition. Review displays the effects of cultivar variation, growing region and physico-chemical compositional status of fruits such as fruit size, fruit weight, fruit colour, juice content, $\mathrm{pH}$ of juice, TSS, ascorbic acid content of juice and total phenolics conclude the pomegranate fruit maturity (Al-Mainman and Ahmad, 2002).

In pomegranate fruit, early harvesting of fruit causes depletion of organoleptic properties and browning of internal husk. Whereas, over-ripen fruits are susceptible to physiological disorders and fungal infections during storage. Inadequate literature is available on how fruit peculiarity and components relate to changes in fruit size in pomegranate cv. 'Mridula'. There is an increased concern about the quality of fruit during development and proceeding to harvest aimed at curtail postharvest devaluation. The present study aimed to investigate developmental dynamic in chemical properties during advancement in fruit growth of pomegranate in sub-tropical conditions.

\section{Materials and Methods}

Sample collection : Fresh fruits of eight year old plants of pomegranate cv. 'Mridula' were picked manually in the morning from Fruit Research Farm, Department of Fruit Science, Punjab Agricultural University, Ludhiana (India) at different developments stages, viz., 30 to 150 DAFB at ten day interval. Harvested fruits were then transported to laboratory in plastic bag for physico-chemical analysis. Nine pomegranate fruits sampled and three replicates were maintained for each analysis and each replicate included three fruits.

Chemical changes : Juice of pomegranate arils of nine fruit were completely extracted by squeezing the aril in muslin cloth. Collected fresh juice was analysed for different chemical compositional changes. Soluble solids content (SSC) were determined with digital refractometer (ATAGO, PAL-1, Model 3810 , Japan) at room temperature, expressed in ${ }^{\circ}$ Brix and subsequent corrections were made at $20^{\circ} \mathrm{C}$ (AOAC, 2000). The titratable acidity (TA) content was determined by titrating juice across $0.1 \mathrm{~N}$ sodium hydroxide, applying phenolphthalein as indicator and sugars content by the methods of AOAC (2000) and results were expressed in percentage. The $\mathrm{pH}$ of juice was determined by digital pH meter (Eutech, Malaysia). Ascorbic acid content was determined according to AOAC (2005) with 2,6dichloro-indophenol titrimetric method and the result were expressed as mg per $100 \mathrm{ml}$ of fruit juice. Total phenolics were determined in triplicates by the Folin-Ciocalteau (Folin-C.) colorimetric method (Makker, 2000) and the results were expressed as gallic acid equivalents as (GAE) per litre of pomegranate juice.

Statistical analysis : The data for nine replication was analyzed for analysis of variance (ANOVA) and significant difference among the means were determined by LSD at $p<0.05$ using the SAS version 9.3 (SAS Institute Inc., Cary, NC, USA). Pearson correlation was used to investigate the relationship between the selected attributes associated with fruits maturity and in order to find the inter-relationship among the investigated fruit parameters 'principal component analysis' (PCA) was used.

\section{Results and Discussion}

A gradual and significant $(p<0.05)$ increase in soluble solids contents of the aril juice were detected with the

Table 1 : Pearson correlation coefficients ( $r$ ) among chemical indices associated during fruit developments

\begin{tabular}{|c|c|c|c|c|c|c|c|c|c|}
\hline & SSC & TA & SSC/TA & $\mathrm{pH}$ & $\begin{array}{l}\text { Total } \\
\text { sugars }\end{array}$ & $\begin{array}{l}\text { Reducing } \\
\text { sugars }\end{array}$ & $\begin{array}{l}\text { Non-reducing } \\
\text { sugars }\end{array}$ & Vitamin C & $\begin{array}{l}\text { Total } \\
\text { phenolics }\end{array}$ \\
\hline SSC & 1 & & & & & & & & \\
\hline TA & -0.958 & 1 & & & & & & & \\
\hline SSC/TA & 0.950 & -0.987 & 1 & & & & & & \\
\hline $\mathrm{pH}$ & 0.930 & -0.981 & 0.990 & 1 & & & & & \\
\hline Total sugars & 0.873 & -0.929 & 0.954 & 0.955 & 1 & & & & \\
\hline Reducing sugars & 0.888 & -0.937 & 0.963 & 0.960 & 0.999 & 1 & & & \\
\hline Non-reducing sugar & 0.786 & -0.865 & 0.892 & 0.904 & 0.975 & 0.962 & 1 & & \\
\hline Vitamin C & 0.862 & -0.925 & 0.962 & 0.960 & 0.910 & 0.918 & 0.849 & 1 & \\
\hline Total phenolics & -0.969 & 0.962 & -0.953 & -0.944 & -0.917 & -0.925 & -0.856 & -0.870 & 1 \\
\hline
\end{tabular}

Significance at $p<0.05$ 


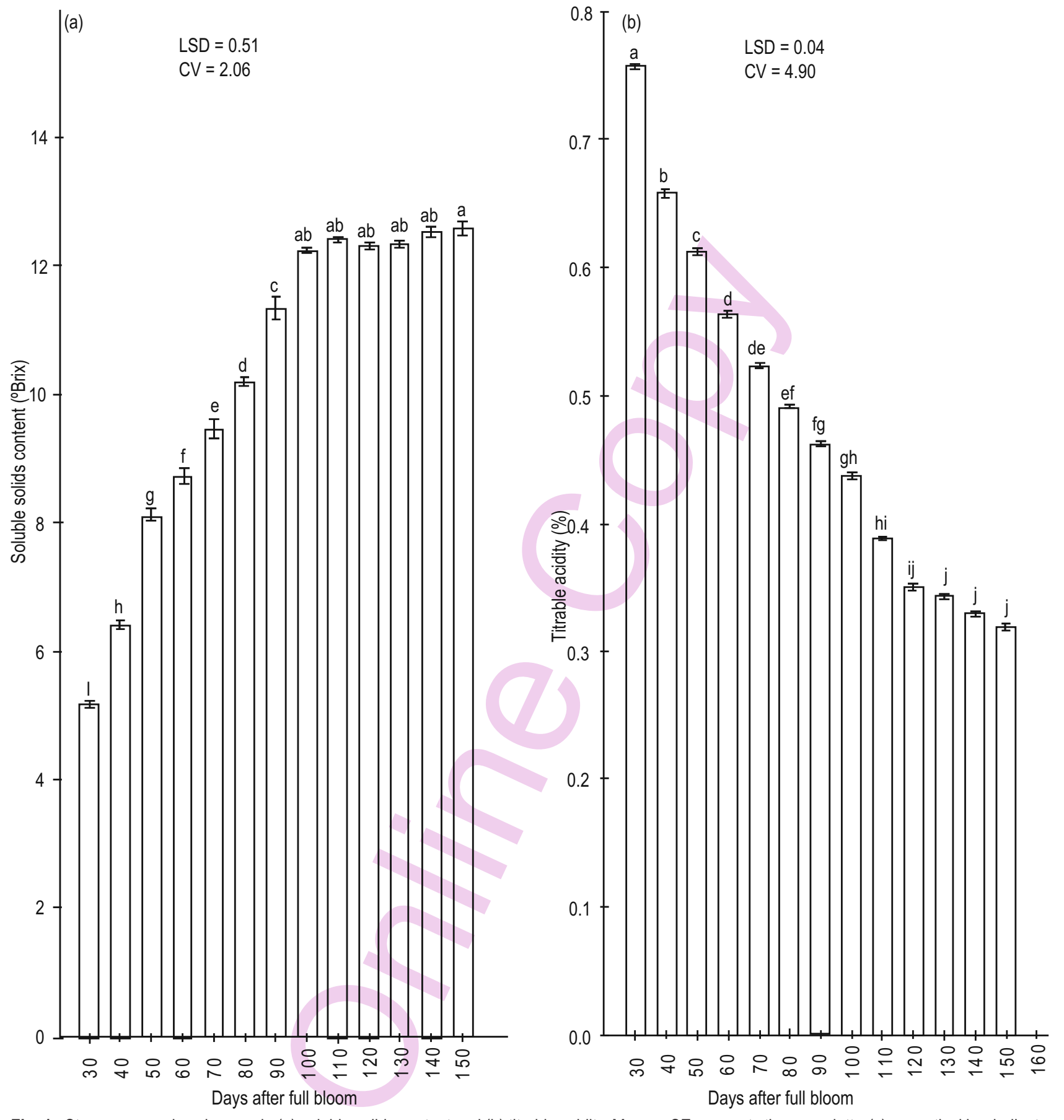

Fig. 1 : Stage progression changes in (a) soluble solids content and (b) titrable acidity. Mean \pm SE, presents the same letter(s) on vertical bar indicate statistically non-significantly different compare to previous sample $(p<0.05)$

advancement in fruit maturity (Fig. 1a). During early and midseason of fruit development the SSC increased significantly from 30 DAFB ( $5.17^{\circ}$ Brix) to 100 DAFB ( $12.10^{\circ}$ Brix), however at later stages increment in soluble solids content was very slow. Minimum Soluble solids content were recorded at 30 DAFB (5.17 $\left.{ }^{\circ} \mathrm{Brix}\right)$ and maximum at $150 \mathrm{DAFB}\left(12.61^{\circ} \mathrm{Brix}\right)$. However, the rate of change of soluble solids content was maximum from 30 DAFB (5.17 ${ }^{\circ}$ Brix) to 50 DAFB ( $7.95^{\circ}$ Brix), and minimum from 140
$\operatorname{DAFB}\left(12.53^{\circ}\right.$ Brix $)$ to 150 DAFB $\left(12.61^{\circ} \mathrm{Brix}\right)$.

Pomegranate juice contains citric acid, maleic acid, fumaric acid, tartaric acid and lactic acids but major acid accounting for titratable acidity is citric acid (Melgarejo et al., 2000). TA content of aril juice followed a decreasing trend as the fruit approached towards maturity stage (Fig. 1b). A significant ( $p$ $<0.05$ ) decrease in TA content of fruit occurred between 30 DAFB 


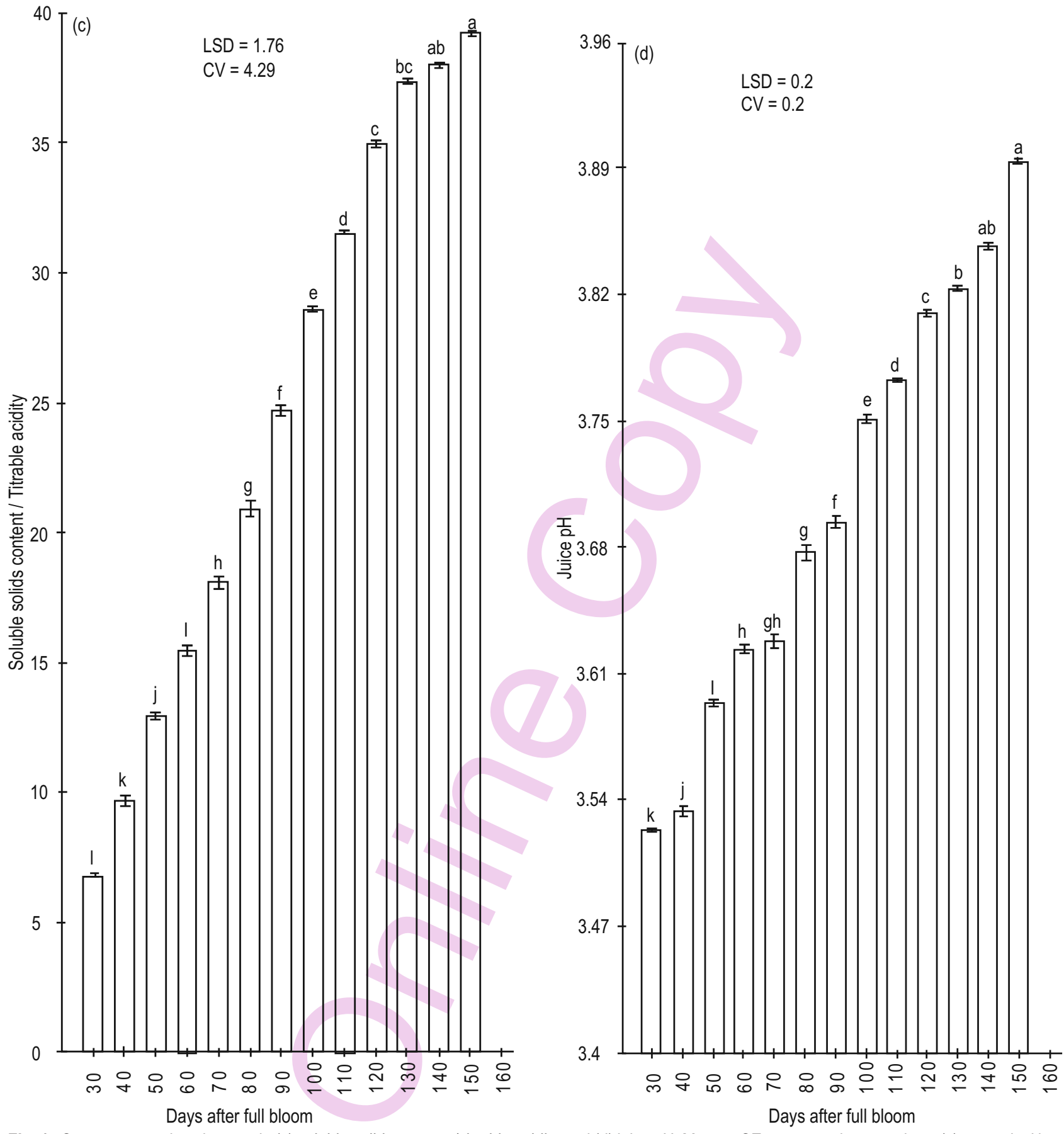

Fig. 1 : Stage progression changes in (c) soluble solids content / titrable acidity and (d) juice pH. Mean \pm SE, presents the same letter(s) on vertical bar indicate statistically non-significantly different compare to previous sample $(p<0.05)$

to 60 DAFB. Subsequently, a non-significant decrease in TA between adjacent intervals was noted till 150 DAFB. The maximum TA content was recorded as $0.76 \%$ at earlier stage of fruit development (30 DAFB) and minimum was recorded as $0.32 \%$ at 150 DAFB. During fruit growth and development about 2.38 fold decreases in TA between 30 DAFB $(0.76 \%)$ to 150 DAFB $(0.32 \%)$ was noticed. However, the rate of change in juice TA was recorded maximum between 30 DAFB $(0.76 \%)$ to 40 DAFB
(0.66\%) and minimum between 140 DAFB to 150 DAFB.

A significant increase in SSC/TA ratio was recorded as fruit progressed towards the maturity (Fig. 1c). The rate of increase in SSC/TA ratio was recorded maximum from 80 DAFB (20.87) to 90 DAFB (24.72), closely followed by 90 to 100 DAFB i.e., from 24.72 to 28.56 , respectively, and the minimum change was recorded from 140 DAFB (38.02) to 150 DAFB (39.25). Decrease in the 

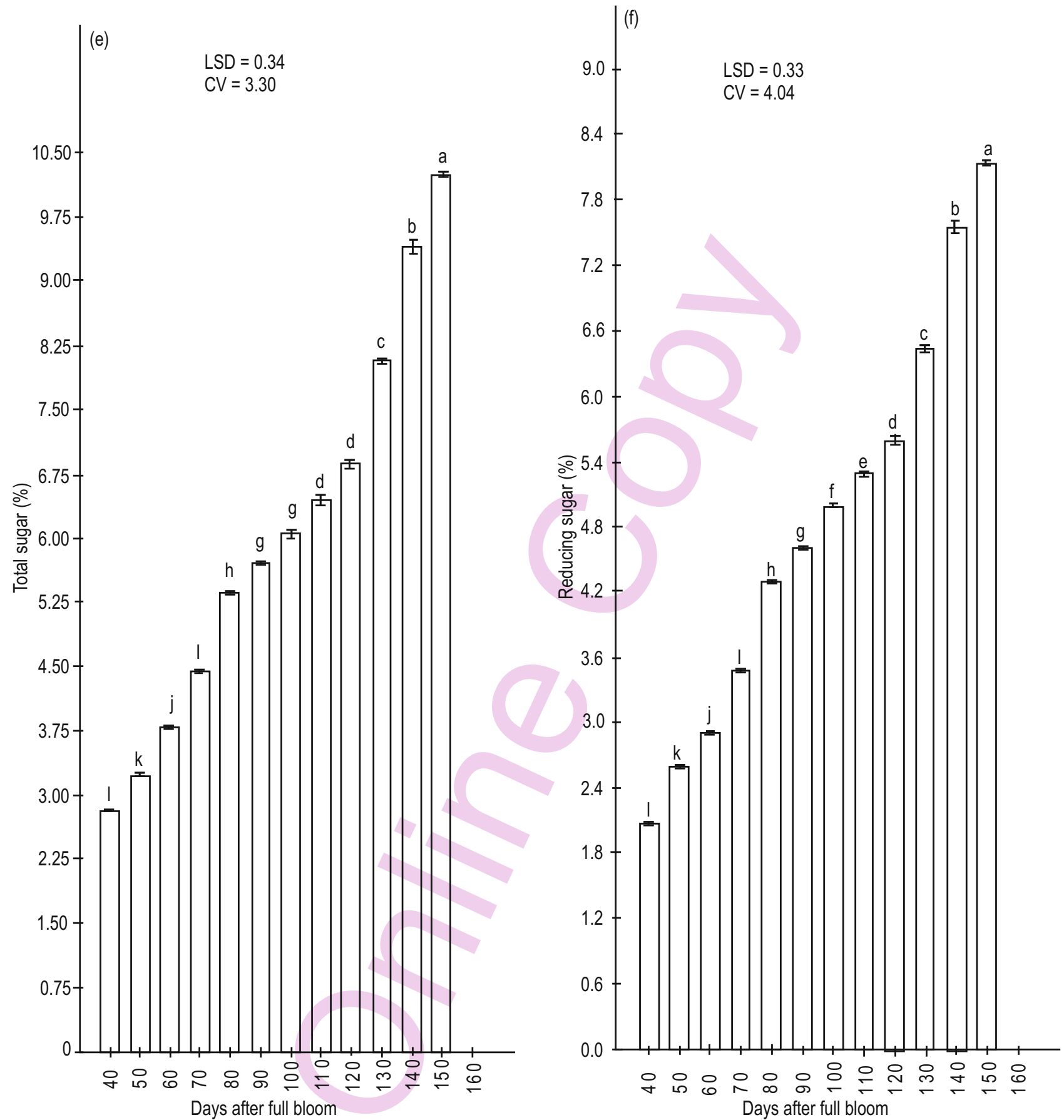

Fig. 1 : Stage progression changes in (e) total sugar and (f) reducing sugar. Mean \pm SE, presents the same letter(s) on vertical bar indicate statistically non-significantly different compare to previous sample $(p<0.05)$

content of juice TA with a gradual increase in SSC during fruit advancement may be resulted into the elevated TSS/TA ratio.

The augment in SSC in pomegranate could be explained by the augmentation of hexose sugars (Shulman et al., 1984). Similar trend in SSC during fruit development was also recorded earlier workers (Borochov-Neori et al., 2009 and Zarei et al.,
2011) in pomegranate. A gradual decrease in TA, concomitant with increased in the SSC and total sugars content is an inherent process during ripening of pomegranate to impart the characteristic flavour (Kulkarni and Aradhya, 2005). Prasad et al., (1999) reported that the increase in SSC/TA ratio in pomegranate juice is due to increase in sugar content in juice and reduction in acidity with maturity. 


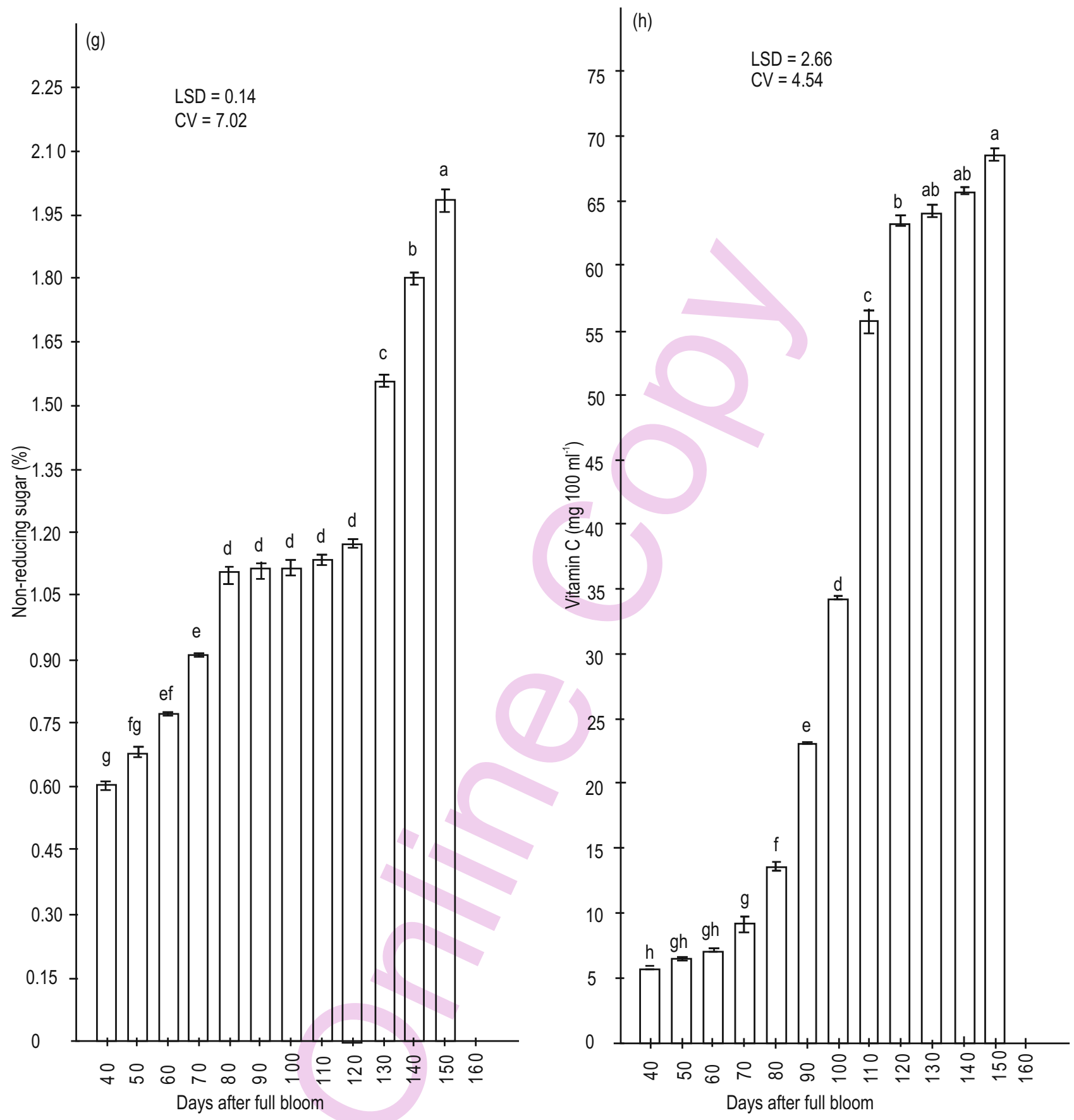

Fig. 1 : Stage progression changes in (g) non-reducing sugar and (h) Vitamin C. Mean \pm SE, presents the same letter(s) on vertical bar indicate statistically non-significantly different compare to previous sample $(p<0.05)$

The $\mathrm{pH}$ of aril juice increased significantly and was static till complete aril development (Fig. 1d). The minimum value of juice $\mathrm{pH}$ was recorded as 3.51 during 30 DAFB and maximum was 3.9 at 150 DAFB. The rate of change in $\mathrm{pH}$ was maximum from 40 DAFB - 50 DAFB and the minimum was recorded between 140 DAFB and 150 DAFB. Decrease in juice TA may have resulted into increment in juice $\mathrm{pH}$ throughout the fruit growth and hence, both the parameters were inversely correlated. This is in agreement with the result of Borochov-Neori et al. (2009); Zarei et al. (2011). However, the juice pH of 'Bhagwa' cultivar of pomegranate decreased from early immature to early half-ripe stage, but further changes were in significant until the full ripe stage (Fawole and Opara, 2013c).

Fig. 1e-g reveals that the total sugars content of fruit juice continued to increase significantly $(p<0.05)$ throughout the 


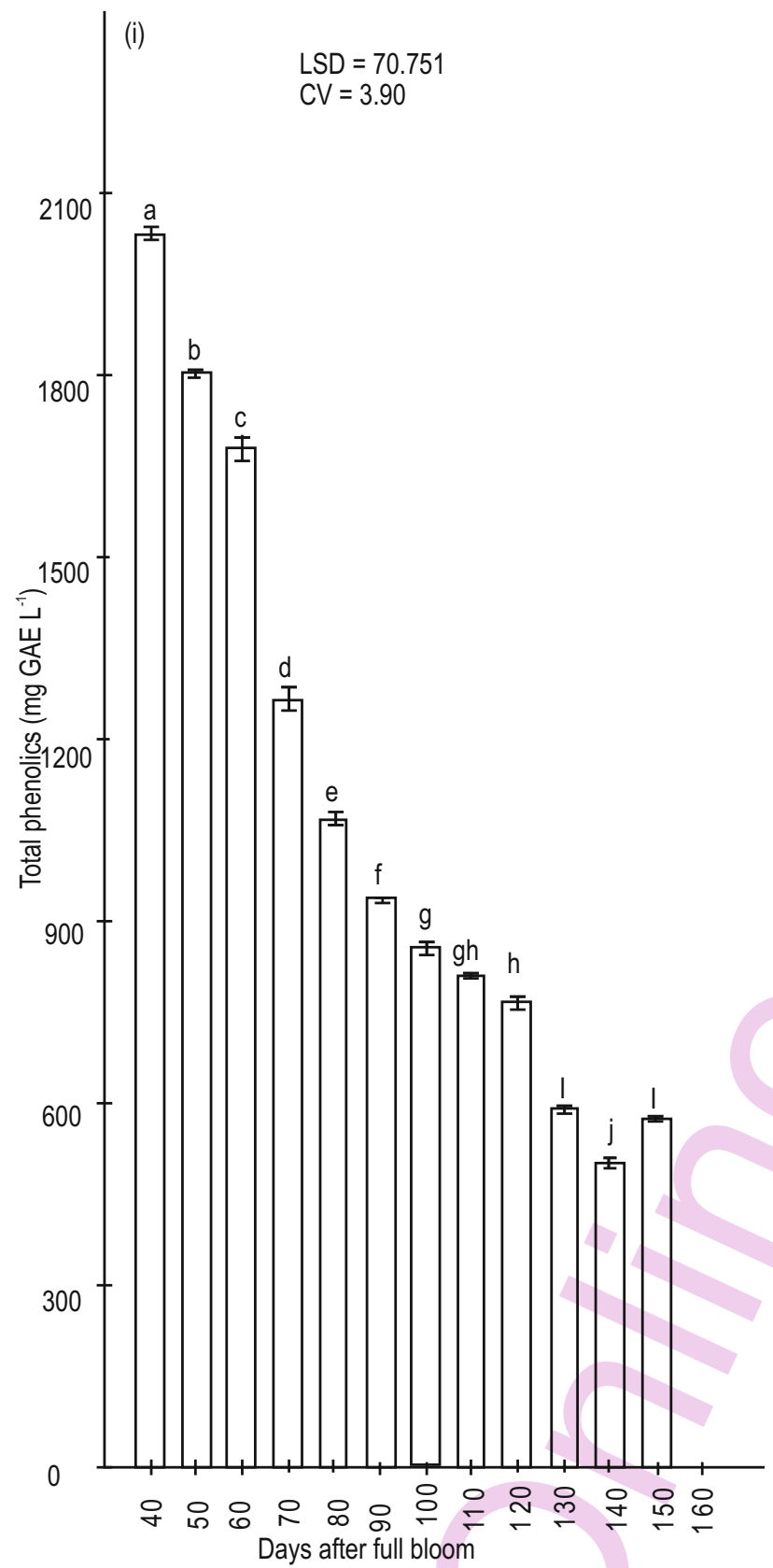

Fig. 1 : Stage progression changes in (i) total phenolics. Mean \pm SE, presents the same letter(s) on vertical bar indicate statistically nonsignificantly different compare to previous sample $(p<0.05)$

course of study. The level of total sugars, reducing sugar and nonreducing sugars was recorded lowest on the first sampling (40 DAFB) as $2.72 \%, 2.07 \%$ and $0.61 \%$, respectively and recorded highest during final sampling (150 DAFB) as $10.28 \%, 8.15 \%$ and $2.02 \%$. The rate of change in total sugars and reducing sugars was maximum recorded from 130 DAFB $(8.11 \%$ and $6.46 \%$, respectively) to 140 DAFB (9.46\% and $7.54 \%$, respectively). Whereas, the increase in non-reducing sugars was highest from

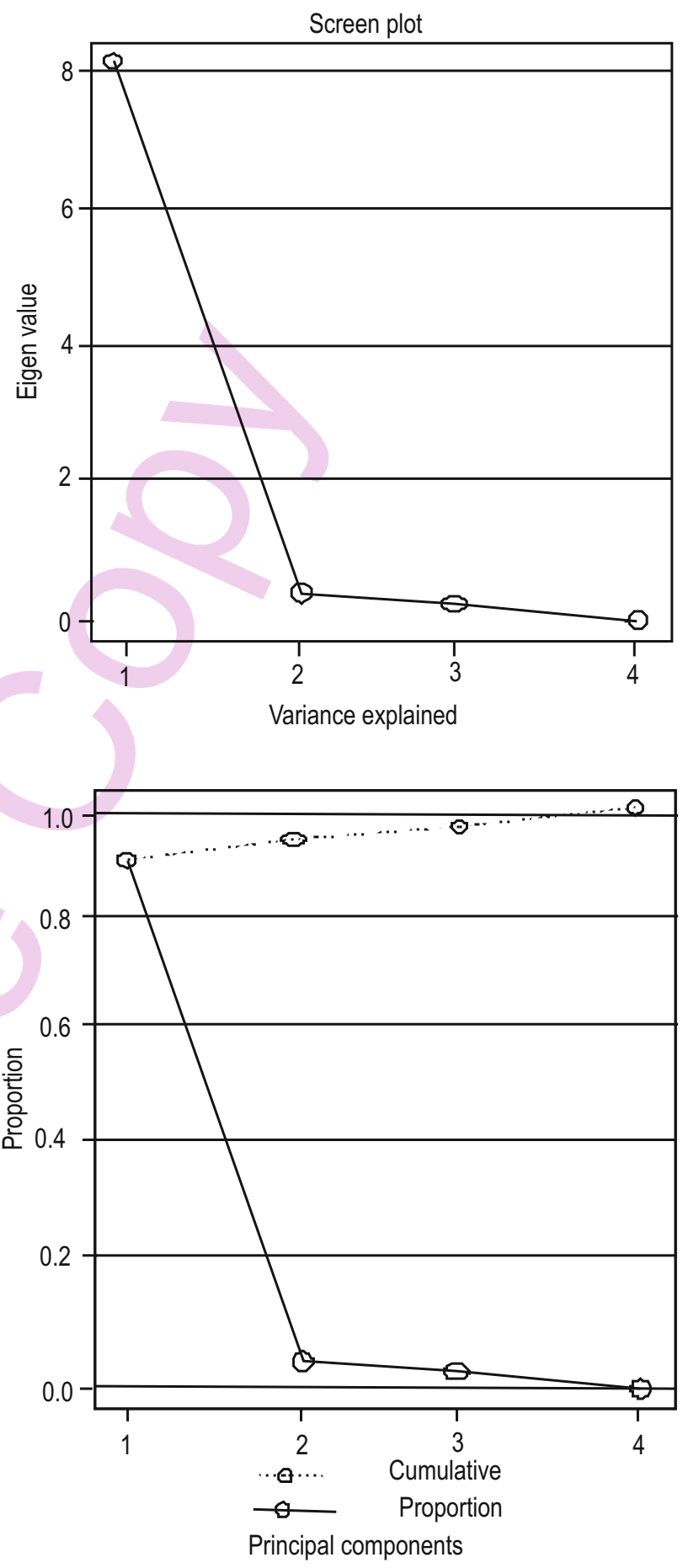

Fig. 2 : Scree plot of variance explained by each factor of principal components

120 DAFB (1.18 \%) to 130 DAFB (1.57 \%), but was recorded minimum between $90 \operatorname{DAFB}(1.09 \%)$ and $100 \operatorname{DAFB}(1.10 \%)$.

The present investigation of total sugars increases during fruit advance towards the ripening, confirms the findings of Legua et al. (2000), Kulkarni and Aradhya (2005). A rapid increase in 

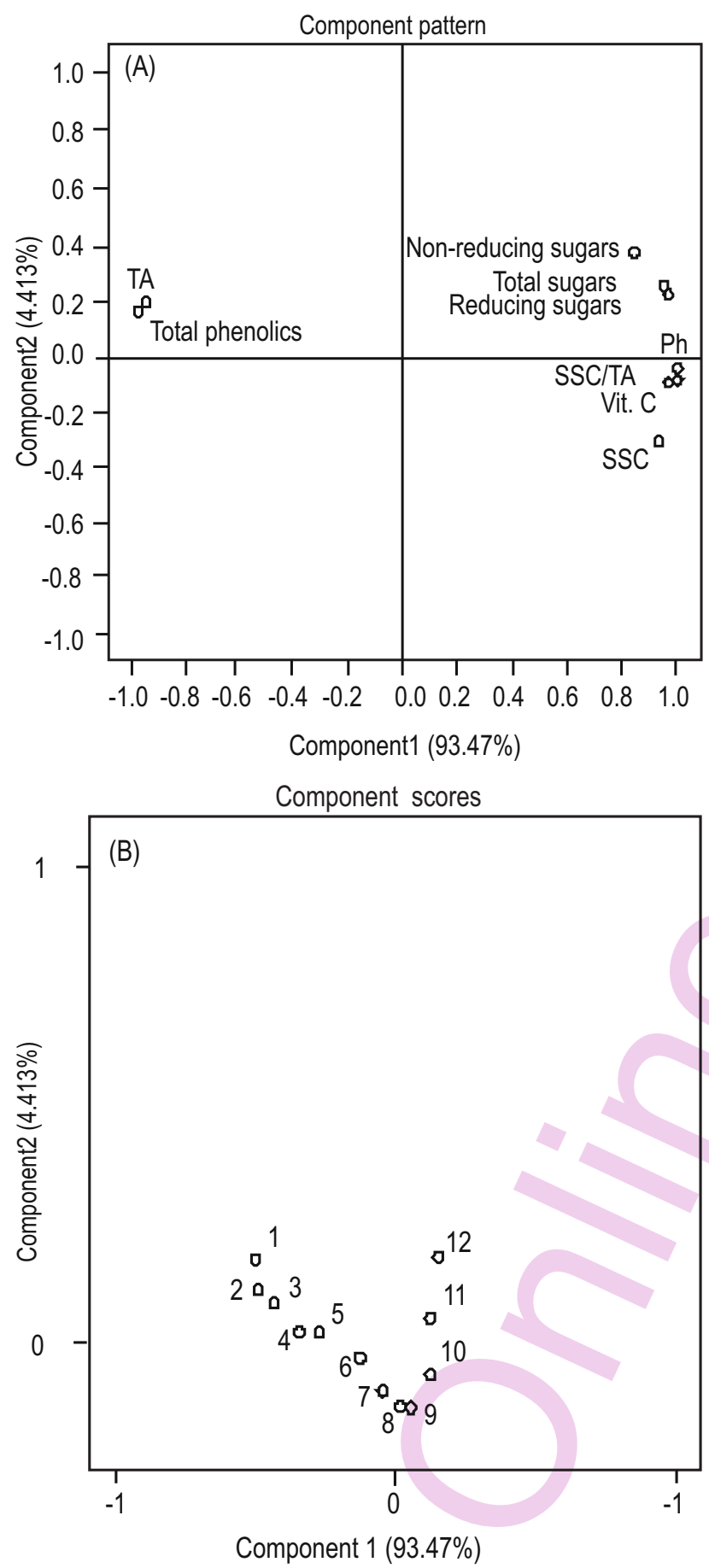

Fig. 3 : Principal component analysis of the first two factors (F1 and F2) showing dispersion of 'Mridula' pomegranate fruit cultivar based on the measured parameters at fruit maturity stages; components pattern $(A)$ and component score (B)

total sugars in pomegranate from immature to early half-ripe stage was due to intense fruit expansion during maturity stages followed by a comparative delay, but significant accretion of sugars until full-ripening stage (Fawole and Opera, 2013b).
A significant increase in Vitamin C content of aril juice was acclaimed during the fruit development of pomegranate fruit (Fig. 1h). Vitamin $C$ content of juice increased sharply from $5.93 \mathrm{mg}$

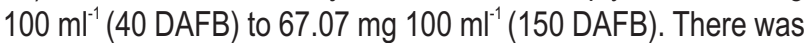

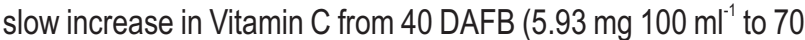

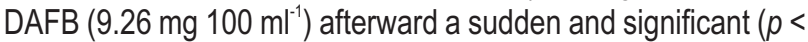

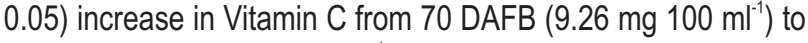
120 DAFB (63.33 mg $100 \mathrm{ml}^{-1}$ ) was noted. Overall, 11.32 times increase in Vitamin $\mathrm{C}$ content of aril juice was noted during fruit development. A similar trend in increase in Vitamin C content was reported by Shwartz et al. (2009) in pomegranate cv. Wonderful. However, Vitamin C content decreased during fruit advancement toward maturity (Kulkarni and Aradhya, 2005) for Ganesh cultivar, Al-Maiman and Ahmad (2002) for Taifi cultivar and Zarei et al. (2011) in Rabbab-e-Fars cultivar of pomegranate, respectively.

Pomegranate juice is rich in phenolic compounds which have synergistics and additive effects on its pharmacological activities (Seeram et al., 2005). Total phenolics content of the aril juice followed a decreasing trend as the pomegranate fruit approached maturity stage (Fig. 1i). The highest total phenolics content in aril juice was recorded at early immature stage (40 DAFB, $2029.57 \mathrm{mg} \mathrm{GAE/L),} \mathrm{but} \mathrm{least} \mathrm{recorded} \mathrm{at} 140$ DAFB (496.76 mg GAE/L). Overall, depletion in total phenolics was $70.98 \%$ during fruit development. A higher rate of depletion in total phenolics was recorded between 60 DAFB (1681.96 mg GAE/L) and 70 DAFB (1292.48 mg GAE/L) whereas minimum recorded between 100 DAFB (852.74 mg GAE/L) to 110 DAFB (815.05 mg $\mathrm{GAE} / \mathrm{L})$. The loss of astringency is one of the desirable changes that occur during maturation and ripening of pomegranate and is primarily due to decrease in phenolic compounds during fruit maturation (Kulkarni and Aradhya, 2005; Shwartz et al. 2009; Labbe et al., 2010). Reduction in TP content in the present study is similar the finding of Weerakkody et al. (2010), where reduced total phenolics was recorded in Wonderful pomegranate cultivar during the early season.

Pearson correlation was used to investigate the relationship between selected attributes associated with fruit maturity (Table 1) of the pomegranate. Soluble solid content showed significant and positive correlation with SSC/TA $\left(r^{2}=\right.$ $0.950), \mathrm{pH}\left(r^{2}=0.930\right)$, total sugars $\left(r^{2}=0.873\right)$, reducing sugars $\left(r^{2}=0.888\right)$ and Vitamin $C\left(r^{2}=0.862\right)$. Also, SSC correlated negatively strong with $\operatorname{TP}\left(r^{2}=-0.969\right)$, this relationship reflected the correlations of TA between SSC/TA $\left(r^{2}=-0.987\right), \mathrm{pH}\left(r^{2}=\right.$ $0.981)$, total sugars $\left(r^{2}=-0.929\right)$, reducing sugars $\left(r^{2}=-0.937\right)$, non-reducing sugars $\left(r^{2}=-0.865\right)$ and Vitamin $C\left(r^{2}=-0.925\right)$ except TP $\left(r^{2}=0.962\right)$. This further suggested that SSC/TA was positively correlated with $\mathrm{pH}$, sugars and Vitamin $\mathrm{C}$ but negatively correlated with total phenolics. Furthermore, the relationship between total sugar and total phenolics was negatively correlated. Pearson correlation coefficient ( $r$ ) among the selected indices associated fruit maturity were similar to the study of Fawole and Opara (2013a) in pomegranate cvs. 'Ruby' and 
'Bhagwa', respectively.

Furthermore, to access an extensive view on the metabolic shift that exit during fruit advancement, the whole info set was subjected to Principal Component Analysis. The overall variability is interpreted by four factors (F1 - F4), with the first two factors of PCA showing correlation of $97.88 \%$ (Fig. 2). The first factor (F1) was responsible for $93.47 \%$ total variations, however the second factor (F2) elucidated only $4.41 \%$ of total variations, indicating that the maximum variations in fruit maturity indices was interpreted by F1 (Fig. 3A). A general view of the PCA showed that young fruits had higher titratable acid and total phenolics, while fully mature fruits have higher SSC which is correlated with SSC/TA, pH, Vitamin C and sugars of fruits juice. Negative scores along F1 corresponded to late immature fruits at 80 DAFB. Full mature fruits had high positive scores along F1, while low negative scores were half mature at $110 \mathrm{DAFB}$ (Fig. 3B). In the present study, decrease in acidity and TP in immature fruits was also characterized by the shift from right to left, reflecting the beginning of maturity process between 110 DAFB to 130 DAFB. The beginning of ripening process in the cultivar could well ascribed to fruit at 110 DAFB, where consolidation of fruit biochemical indices seemed to be at equilibrium (Fig. 3A and Fig. $3 \mathrm{~B})$. These results are similar to those reported by Fawole and Opara (2013b) where maturity of 'Bhagwa' pomegranate fruit could be fixed around 165 DAFB where fruit were characterize by intense chemical changes in fruitjuice.

\section{Acknowledgments}

We thank Dr. M.I.S. Gill, Head of the Department, Fruit Science, Punjab Agricultural University, Ludhiana for his resourceful, financial support and encouragement in carrying out the research. The authors are grateful to Ms. Annu Verma (Project Fellow) and Navdeep Kaur (Project Fellow) for their support during the research.

\section{References}

Al-Maiman, S.A. and D. Ahmad: Changes in physical and chemical properties during pomegranate (Punica granatum L.) fruit maturation. Food Chem.,76, 437-441(2002).

Al-Said, F.A., L.U. Opara and R.A. Al-Yahyali: Physico-chemical and textural quality attributes of pomegranate cultivars (Punica granatum L.) grown in the Sultanate of Oman. J. Food Eng., 90, 129-134 (2009).

A.O.A.C.: Official Methods of Analysis. Association of Official Analytical Chemist, Benjamin Franklin Station, $15^{\text {th }}$ Edn., Washington DC, USA(2000).

A.O.A.C.: Official Methods of Analysis. Association of Official Analytical Chemist, Benjamin Franklin Station, $15^{\text {th }}$ Edn., Washington DC, USA(2005).

Borochov-Neori, H., S. Judeinstein, E. Tripler, M. Harari, A. Greenberg, I. Shomer and D. Holland: Seasonal and cultivar variations in antioxidant and sensory quality of pomegranate (Punica granatum
L.) fruit. J. Food Compos. Anal., 22, 189-195 (2009).

Fawole, O.A. and U.L. Opara: Changes in physical properties, chemical and elemental composition and antioxidant capacity of pomegranate (cv. Ruby) fruit at five maturity stages. Sci. Hort., $150,37-46$ (2013a).

Fawole, O.A. and U.L. Opara: Effects of maturity status on biochemical content, polyphenol composition and antioxidant capacity of pomegranate fruit arils (cv. Bhagwa). S. Afr. J. Bot., 85, 23-31 (2013b).

Fawole, O.A. and U.L. Opara: Influence of fruit developmental and maturity stages on chemical, phytochemical and antioxidant properties of pomegranate juice. Acta Hort., 1007, 461-470 (2013c).

Gil, M.I., A.T. Berberan, B.H. Pierce, D.M. Holcroft and A.A. Kader: Antioxidant activity of pomegranate juice and its relationship with phenolic composition and processing. J. Agr. Food Chem., 48, 4581-4589 (2000).

Labbe, M., A. Pena and C. Saenz: Antioxidant capacity and phenolic composition of juice from pomegranate stored in refrigeration. Inter. Conf. Food, 48, 88-95(2010).

Legua, P., P. Melgarejo, M. Martinez and F. Hernandez: Evolution of sugars and organic acid content in three pomegranate cultivars (Punica granatum L.). Option Mediterran., 42, 99-104 (2000).

Kulkarni, A.P. and S.M. Aradhya: Chemical changes and antioxidant activity in pomegranate arils during fruit development. Food Chem., 93, 319-324 (2005).

Makkar, H.P.S.: Quantification of tannins in tree foliage. A laboratory manual for the FAO/IAEA Coordinated Research Project on 'use of nuclear and related techniques to develop simple tannin assay for predicting and improving the safety and efficiency of feeding ruminants on the tanniniferous tree foliage'. Joint FAO/IAEA Division of Nuclear Techniques in Food and Agriculture, Vienna, Austria (2000).

Melgarejo, P., D.M. Salaze and F. Artes: Organic acids and sugars composition of harvested pomegranate fruits. Eur. Food Res. Technol., 211, 185-190 (2000).

Prasad, R.N., G.J. Banker and B.B. Vashishtha: Assessment of maturity in pomegranate on the basis of physico-chemical characteristic in arid regions. Hary. J. Hortic. Sci., 28, 69-70 (1999).

Seeram, N.P., L.S. Adams, S.M. Henning, Y. Nilu, Y. Zhang, M.G. Nair and D. Heber: In vitro, antiproliferative, apoptotic and antioxidant activities of punicalagin, ellagic acid and total pomegranate tannin extract are enhanced in the combination with other polyphenols as found in pomegranate juice. J. Nut. Biochem., 16, 360-367 (2005).

Shulman, Y., L. Fainberstein and S. Lavee: Pomegranate fruit development and maturation. J. Horticul. Sci., 59, 265-74(1984).

Shwartz, E., I. Glazer, I. Bar-Ya'akov, F. Matityahu, I. Bar-ilan, D. Holland and R. Amir: Changes in chemical constituents during the maturation and ripening of two commercially important pomegranate accessions. Food Chem.,115, 965-973 (2009).

Weerakkody, P., J.I. Jobling, M.V. Maria and G. Rogers: The effect of maturity, sunburn and the application of sunscreens on the internal and external qualities of pomegranate fruit grown in Australia. Sci Hort., 124, 57-61 (2010).

Zarei, M., M. Azizi and Z. Bashir-Sadr: Evaluation of physico-chemical characteristics of pomegranate (Punica granatum L.) fruit during ripening. Fruits, 66, 121-29(2011). 